\title{
Platelet-Activating Factor Receptor Ligands Protect Tumor Cells from Radiation-Induced Cell Death
}

\author{
Ildefonso Alves da Silva-Junior*, Barbara Dalmaso, Suellen Herbster, Ana Paula Lepique \\ and Sonia Jancar
}

Instituto de Ciências Biomédicas, Universidade de São Paulo, São Paulo, Brazil

Irradiation generates oxidized phospholipids that activate platelet-activating factor receptor (PAFR) associated with pro-tumorigenic effects. Here, we investigated the involvement of PAFR in tumor cell survival after irradiation. Cervical cancer samples presented higher levels of PAF-receptor gene (PTAFR) when compared with normal cervical tissue. In cervical cancer patients submitted to radiotherapy (RT), the expression

OPEN ACCESS

Edited by:

William Small, Jr.,

Stritch School of Medicine,

United States

Reviewed by: Michael Wayne Epperly, University of Pittsburgh,

United States

James William Jacobberger, Case Western Reserve University, United States

*Correspondence: Ildefonso Alves da Silva-Junior iasjr@usp.br

Specialty section:

This article was submitted to

Radiation Oncology,

a section of the journal

Frontiers in Oncology

Received: 23 October 2017 Accepted: 15 January 2018

Published: 05 February 2018

Citation:

da Silva-Junior IA, Dalmaso B, Herbster S, Lepique AP and Jancar $S$ (2018) Platelet-Activating

Factor Receptor Ligands Protect

Tumor Cells from RadiationInduced Cell Death.

Front. Oncol. 8:10. doi: 10.3389/fonc. 2018.00010 of PTAFR was significantly increased. Cervical cancer-derived cell lines (C33, SiHa, and HeLa) and squamous carcinoma cell lines (SCC90 and SCC78) express higher levels of PAFR mRNA and protein than immortalized keratinocytes. Gamma radiation increased PAFR expression and induced PAFR ligands and prostaglandin E2 (PGE2) in these tumor cells. The blocking of PAFR with the antagonist CV3938 before irradiation inhibited PGE2 and increased tumor cells death. Similarly, human carcinoma cells transfected with PAFR (KBP) were more resistant to radiation compared to those lacking the receptor (KBM). PGE2 production by irradiated KBP cells was also inhibited by CV3988. These results show that irradiation of carcinoma cells generates PAFR ligands that protect tumor cells from death and suggests that the combination of RT with a PAFR antagonist could be a promising strategy for cancer treatment.

Keywords: platelet-activating factor receptor, prostaglandin E2, radiotherapy resistance, cervical cancer, head and neck squamous carcinoma

\section{INTRODUCTION}

Treatments based on cell death represent an effective way of controlling cancer growth locally, and radiotherapy (RT) represents the most effective postoperative treatment for cervical and head and neck squamous cell carcinoma $(1,2)$. However, they have an important drawback, which is the possibility of the exacerbated growth of tumor cells that survived treatment (a phenomenon known as tumor repopulation). Following cell death, homeostatic mechanisms are triggered within tissues, which favor the survival of surrounding cells. Apoptosis-induced proliferation is a physiological process that controls cell replacement in healthy or wounded tissue (3). However, in the tumor microenvironment, the apoptotic cells may promote undesirable proliferation of live radio-resistant tumor cells (4). Correa et al. (5) showed that the addition of apoptotic cells to a sub-tumorigenic dose of murine melanoma promoted tumor engraftment and growth. Later on, it was shown that this apoptosis-induced tumor growth was inhibited if mice were pretreated with antagonists of plateletactivating factor receptor (PAFR) (6). 
Recently, using a mouse model to study irradiation-induced repopulation, we found that in both in vivo and in vitro experiments, irradiated TC- 1 cells stimulated tumor cell proliferation in a PAFR-dependent manner. Irradiation also induced prostaglandin E2 (PGE2) production by a human carcinoma cell line transfected with PAFR (KBP) (7). Huang et al. (8) demonstrated that irradiated tumor cells undergoing apoptosis release factors that stimulate the growth of the surviving tumor cells by a mechanism dependent on the activation of caspase- 3 and PGE2 secretion.

Both lipid mediators are released from membrane phospholipids after the activation of cytoplasmic phospholipase A2. The cleavage of phosphatidylcholine (GPC) generates arachidonic acid (AA) and lyso-GPC. The AA can be enzymatically converted to prostaglandins (9), while the lyso-GPC can be converted to PAF (alkyl-acyl-GPC) by PAF acetyl transferase (10). Besides the PAF generated by the enzymatic process, several oxidized phospholipids are generated by non-enzymatic processes (11). Irradiation generates reactive oxygen species, producing a wide range of oxidized phospholipids that also bind to PAFR $(12,13)$. These lipids exert their actions through G-proteincoupled receptors expressed in many cell types including some tumor cells. The expression of PAFR was shown in human melanoma SKmel-23, human breast cancer cells (MCF7, T-47D, and MDA-MB231), and EL4 cell lymphoma cell lines. The activation of PAFR in tumor cells was shown to increase proliferation $(7,13-15)$ and to induce the expression of antiapoptotic factors in B16F10 melanoma cells (16). Prostaglandin-inducible enzyme cyclooxygenase- 2 is overexpressed in most solid tumors such as colorectal, liver, pancreatic, breast, and lung cancer (17-22), and the sustained biogenesis of PGE2 appears to play roles in tissue remodeling, angiogenesis, cancer cell survival, metastasis, and immune evasion (23-25). Thus, it seems that PAF and PGE2 have a pro-survival effect in tumor cells that express receptors for these mediators.

In the present study, we screened five carcinoma cell lines for the expression of PAFR, the effect of radiation on receptor expression, and the generation of PAF-like molecules and PGE2. Next, we investigated the effect of blocking PAFR or inhibiting prostaglandins in radiation-induced tumor cell survival.

\section{MATERIALS AND METHODS}

\section{Expression Datasets}

Gene Expression Omnibus $\left(\mathrm{GEO}^{1}\right)$ is an open database providing gene expression data and clinical data information. We retrieved cervical cancer datasets from the GSE9750 and GSE3578 and compared PAF-receptor gene expression (PTAFR) among the groups. Data were analyzed by non-parametric Mann-Whitney test to compare groups from GSE9750 and Wilcoxon test to compare paired samples from GSE3578. All statistical tests were two-sided. Datasets were analyzed for outliers using https:// graphpad.com/quickcalcs/grubbs1/. A $P$-value less than 0.05 was considered to be statistically significant.

${ }^{1}$ http://www.ncbi.nlm.nih.gov/geo.

\section{Cell Lines and Culture Conditions}

Cervical cancer-derived cell lines (C33, SiHa, and HeLa) and squamous cell carcinoma cells lines (SCC78 and SCC90) were kindly donated by Professor Luisa Lina Villa (ICESP, Sao Paulo, SP, Brazil). HeLa, SiHa, and SCC90 cell lines are positive for HPV, while C33 and SCC78 cell lines are negative for HPV but have mutated p53. HaCaT, an immortalized keratinocyte used as control, was purchased from the American Type Culture Collection (Manassas, VA, USA). Cells were maintained in RPMI 1640 , supplemented with $10 \%$ FBS (fetal bovine serum), penicillin $(100 \mathrm{U} / \mathrm{mL})$, and streptomycin $(100 \mu \mathrm{g} / \mathrm{mL})$. In addition, we obtained a PAFR-negative human epithelial cell line (KBM) and PAF-receptor-positive (KBP) cells from Dr. J. B. Travers (Department of Dermatology, Indiana University School of Medicine, Indianapolis, IN, USA). These cell lines were cultured in Dulbecco's Modified Eagle's Medium (DMEM, GIBCO, OK, USA) supplemented with $10 \%$ FCS, penicillin (100 U/mL), and streptomycin $(100 \mu \mathrm{g} / \mathrm{mL})$. Cells were regularly tested for Mycoplasma and were free of this contamination. All cell cultures were incubated at $37^{\circ} \mathrm{C}$ under a humidified atmosphere of air containing $5 \% \mathrm{CO}_{2}$.

\section{In Vitro Irradiation of Tumor Cells}

Cell lines were grown on $10-\mathrm{cm}$ dishes to $80-90 \%$ confluence and washed three times with pre-warmed $\left(37^{\circ} \mathrm{C}\right) \mathrm{PBS}$ and then cultured in RPMI medium containing $2 \%$ of fetal bovine serum (FBS) for short-term cultures ( $4 \mathrm{~h}$ ) or $10 \%$ of FBS for long-term cultures $(72 \mathrm{~h})$ as indicated in figure legends. Tumor cells were irradiated with multiple doses of gamma radiation (Gy). Cell irradiation studies were conducted using an IBL 136 cell and animal gamma radiator machine (Compagnie Oris Industrie, France). Settings for the machine were as follows: $d=33 \mathrm{c}$ and dose rate of $251.7 \mathrm{cGy} / \mathrm{min}$. In some experiments, the PAFR antagonist CV3988 (Enzo Life Sciences, Farmingdale, NY, USA) or the vehicle control dimethyl sulfoxide of $0.5 \%$ was pre-incubated for $30 \mathrm{~min}$ before irradiation.

\section{Measurement of PAFR Ligands after Irradiation}

Tumor cells and HaCaT cells $\left(10^{7} \mathrm{~mL}\right)$ were plated in $10-\mathrm{cm}$ dishes and incubated overnight in RPMI supplemented with $10 \%$ FBS. Following incubation, the culture medium was replaced with $2 \mathrm{~mL}$ of pre-warmed $\left(37^{\circ} \mathrm{C}\right)$ Hanks Balanced Salt Solution supplemented with $10 \mathrm{mg} / \mathrm{mL}$ fatty acid-free bovine serum albumin and $2 \mu \mathrm{M}$ Pefabloc, a serine hydrolase inhibitor that blocks PAF degradation (Sigma-Aldrich, St. Louis, MO, USA). The cells were then irradiated with 4-8-Gy doses following a 1 -h incubation. The culture was quenched by the addition of $2 \mathrm{~mL}$ of ice-cold methanol followed by methylene chloride, and lipids were extracted, as previously described [(26-28), p. 50]. The presence of PAFR ligands in lipid extracts was determined by the ability of these extracts to induce interleukin-8 (IL-8) production in KBP cells, as previously described (29). Briefly, $2 \times 10^{5} \mathrm{KBP}$ cells were plated in 12-well plates and cultured overnight in DMEM containing 10\% FBS. The cells were then washed with PBS and incubated with FBS-free DMEM. The cells 
were stimulated with the lipid extracts from irradiated cells, and after $5 \mathrm{~h}$, the supernatants were collected for IL- 8 measurement. The concentration of IL- 8 induced by the lipid extracts was compared with that induced by the stable PAFR agonist cPAF (1-hexadecyl-2-N-methylcarbamoyl glycerolphospho-choline). The concentration of IL- 8 in the supernatants was measured using BD OptEIA ${ }^{\mathrm{TM}}$ ELISA sets (BD Biosciences), according to the manufacturer's instructions.

\section{RNA Analysis for PAFR Expression}

Platelet-activating factor receptor expression was analyzed by quantitative reverse transcription polymerase chain reaction using RNA obtained from HaCaT and tumor cells. Total RNA was isolated using TRIzol Reagent (Life Technologies). For real-time RT-PCR, cDNA was synthesized using the RevertAid $^{\mathrm{TM}}$ First Strand cDNA Synthesis Kit (Fermentas Life Sciences, Ontario, CA, USA), according to the manufacturer's instructions. PCR Master Mix (Power SyBr ${ }^{\circledR}$ Green, Applied Biosystems, Warrington, UK) containing the specific primers was then added. Human PAF receptor forward primer: GGG GAC CCC CAT CTG CCT CA and reverse GCG GGC AAA GAC CCA CAG CA; GAPDH forward primer: GAG TCA ACG GAT TTG GTC GT and reverse primer: TTG ATT TTG GAG GGA TCT CG. Real-time PCR was performed using the
Mx3005PTM Real-Time PCR System (Stratagene). Relative gene expression was calculated using the $2^{-\Delta \Delta C T}$ method, as previously described (30). Results are presented as a fold increase relative to non-irradiated cells.

\section{Flow Cytometry for PAFR Expression}

Tumor cells and HaCaT cells $\left(10^{7} \mathrm{~mL}\right)$ were incubated overnight in a medium supplemented with $10 \%$ FBS. Following incubation, the culture medium was replaced with $2 \mathrm{~mL}$ of ice-cold phosphate buffer solution (PBS), and the cells were removed with a rubber policeman cell scraper and harvested by centrifugation at $250 \times g$ for $5 \mathrm{~min}$. Following centrifugation, the cell pellet was washed and resuspended in the staining buffer (PBS, FCS $1 \%$, and sodium azide $0.1 \%$ ) containing the primary antibody (rabbit IgG to PAFR 1:100 dilution in staining buffer; Cayman Chemical, Ann Arbor, MI, USA). Following a 30-min incubation, the cells were washed and resuspended in staining buffer containing Alexa Fluor 647-goat anti-rabbit IgG secondary antibody (1:100 dilution in staining buffer; Invitrogen Life Technologies, Carlsbad, CA, USA). Cells incubated with secondary antibody only were used to control for background fluorescence. The expression of the PAFR was analyzed by flow cytometry. During data acquisition, the doublets were excluded using gates in FSC-A vs. FSC-H.
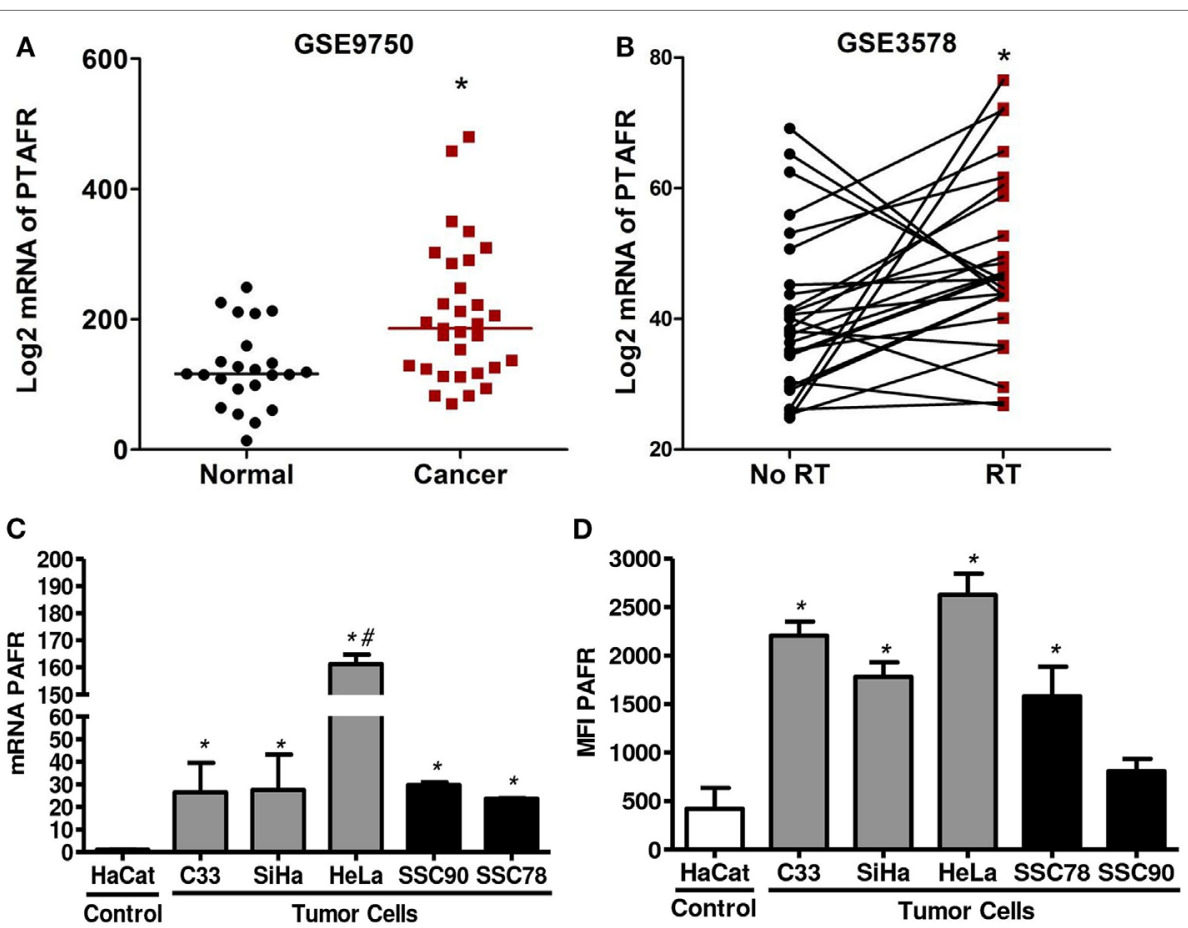

FIGURE 1 | Platelet-activating factor receptor (PAFR) expression was significantly upregulated in cervical invasive carcinomas and cervical cancer-derived cell lines. (A) Analysis PAFR (PTAFR) was increased in invasive carcinomas when compared with normal cervical tissues (GSE9750; $p=0.0044$ ). (B) The PTAFR expression was upregulated in cervical tumors from patients who underwent radiotherapy when compared with biopsies taken before treatment (GSE3578; $p=0.0208$ ). These two cervical cancer datasets were retrieved from GEO web database. (C) PAFR mRNA expression was analyzed by RT-qPCR in cervical tumor cells (C33, SiHa, and HeLa), head and neck squamous cell carcinoma lineage (SCC90 and SCC78), and a control keratinocyte (HaCaT). Data are shown as the mean \pm SD of the comparative delta-CT related to HaCaT of three independent experiments. (D) Median fluorescence intensity (MFI) of PAFR protein expression in the cell membrane. Data were obtained from three independent experiments. ${ }^{*} P<0.05$ comparing the tumor cells with the control keratinocyte HaCaT. 


\section{ELISA Measurement of PGE2}

To measure PGE2 secretion by tumor cells, $10^{6}$ cells per well were plated in $10-\mathrm{cm}$ dishes and incubated overnight. The cells were treated with the prostaglandin inhibitor indomethacin (SigmaAldrich, St. Louis, MO, USA) or the PAFR antagonist CV3988 for $30 \mathrm{~min}$ prior to Gy treatment. The supernatants from the cells were collected $1 \mathrm{~h}$ after cell irradiation, and PGE2 levels in the supernatants were measured by ELISA (Cayman Chemical, Minneapolis, MN, USA).

\section{Cell Death Assay}

The carcinoma cell lines $\left(2 \times 10^{5}\right)$ treated with different doses of radiation ( 4 or $8 \mathrm{~Gy}$ ) were incubated in RPMI $10 \%$ FBS at $37^{\circ} \mathrm{C}$ with $5 \% \mathrm{CO}_{2}$ for 72 hs. Cell death was assessed by labeling the tumor cells with annexin V FITC ( $5 \mu \mathrm{L}$ per sample,
BD Biosciences) and propionate iodide (PI) $(10 \mu \mathrm{L}$ per test, BD Biosciences) for $15 \mathrm{~min}$ and then analyzed by flow cytometry using BD FACS Calibur (BD Biosciences) and FlowJo Version 5.0 software (Ashland, OR, USA). The cells positive for both annexin $\mathrm{V}$ and PI were considered as undergoing cell death.

\section{Statistical Analysis}

Data are represented as mean \pm SD unless otherwise indicated and were analyzed using the Prism 5.0 statistical program (GraphPad Software, San Diego, CA, USA). Comparisons among groups were performed by analysis of variance followed by the Bonferroni multiple comparison test. A two-sided $P<0.05$ was considered to be statistically significant. Each experiment was repeated at least three times.
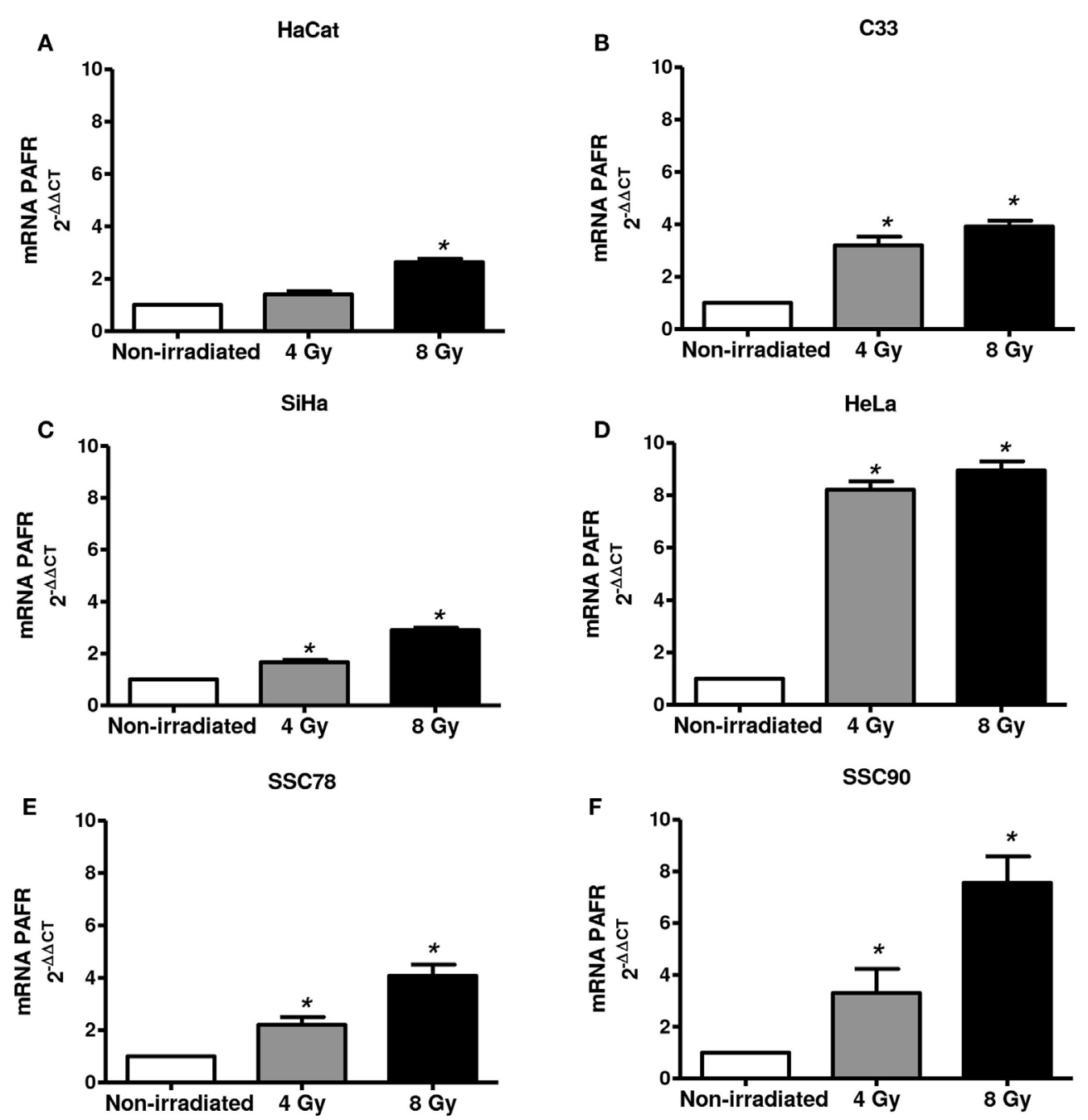

FIGURE 2 | Irradiation of tumor cells increases platelet-activating factor receptor (PAFR) expression. Immortalized keratinocytes HaCaT (A), human cervical carcinoma cell lines C33 (B), SiHa (C), and HeLa (D) and head and neck squamous cell carcinoma lineage SCC78 (E) and SCC90 (F) were cultured in RPMI $2 \%$ fetal bovine serum at $37^{\circ} \mathrm{C}$, and $5 \% \mathrm{CO}_{2}$ was irradiated with 4 or $8 \mathrm{~Gy}$. After $6 \mathrm{~h}$, PAFR mRNA expression was analyzed by RT-qPCR. Data are shown as the mean $\pm \mathrm{SD}$ of three independent experiments. ${ }^{*} P<0.05$ comparing irradiated with non-irradiated groups. 


\section{RESULTS}

\section{Irradiation of Tumor Cells Increases PAFR Expression and Induces PAF-Like Lipids and PGE2}

We first analyzed PAFR (PTAFR) expression in two cervical cancer datasets retrieved from GEO web database. ${ }^{2}$ We observed that PTAFR expression was upregulated in invasive carcinomas ( $n=33$ ) when compared with age-matched normal cervical tissues from hysterectomy specimens $(n=19)$ (GSE9750, Figure 1A) (31). In the second series (GSE3578), we found that

${ }^{2}$ https://www.ncbi.nlm.nih.gov/gds. the mRNA level of PTAFR was increased in cervical tumors $(n=26)$ after the patients underwent RT treatment protocol (Figure 1B). Biopsies were taken before and 1 week after the start of therapy. For the after-treatment biopsy, the patients had received 9 Gy of whole pelvic irradiation, part of a 30.6-Gy RT protocol to the whole pelvis, plus an additional dose to parametria with central shielding to complete 50.6-Gy protocol treatment, along with ${ }^{192} \mathrm{Ir}$ high-dose rate intracavitary [described in Ref. (32)].

To improve this observation, we also evaluate the expression of PAFR in three cervical carcinoma cell lines (C33, SiHa, and HeLa) and in two squamous carcinoma cell lines (SCC90 and SCC78) compared to an immortalized keratinocyte (HaCaT). Our results showed that all carcinoma tumor cell lines express
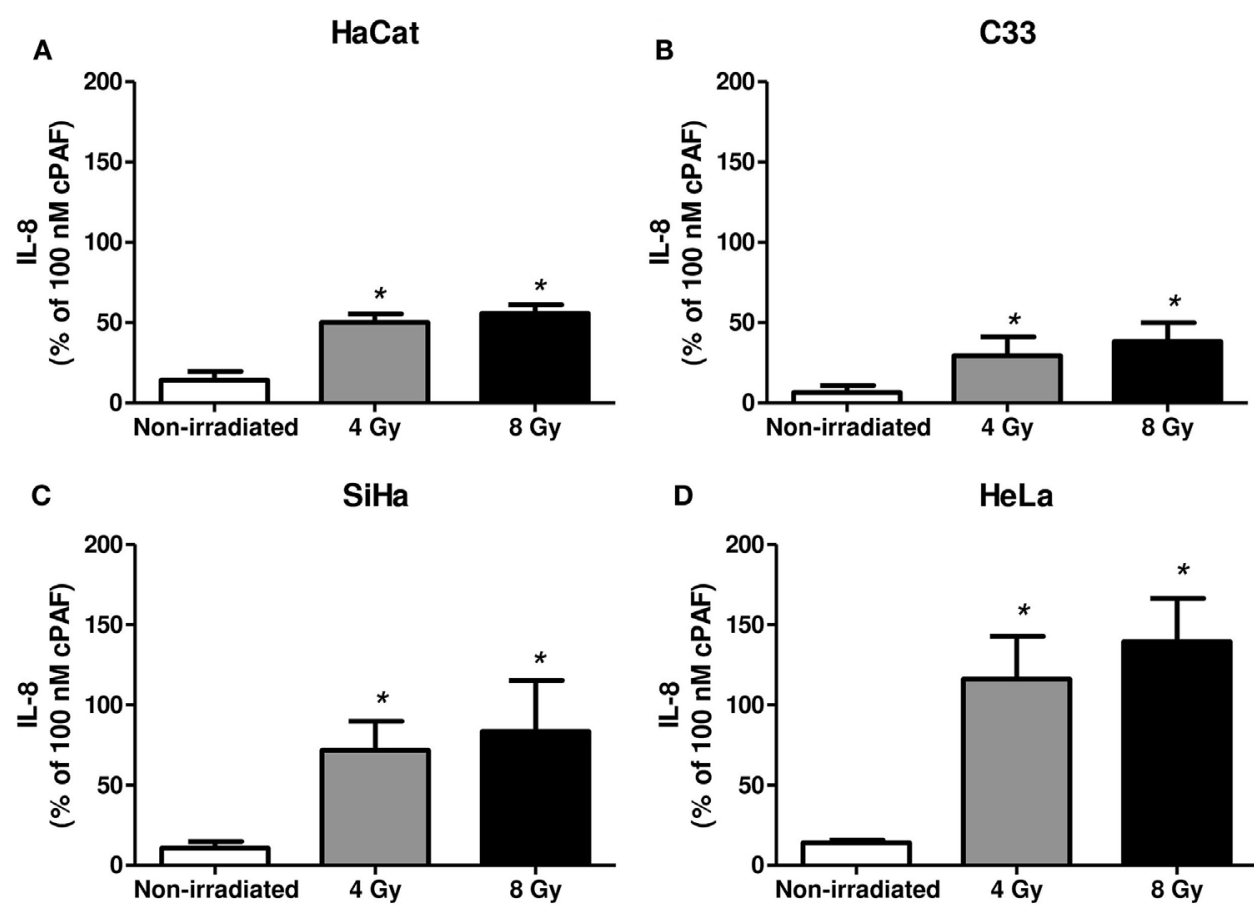

D

HeLa
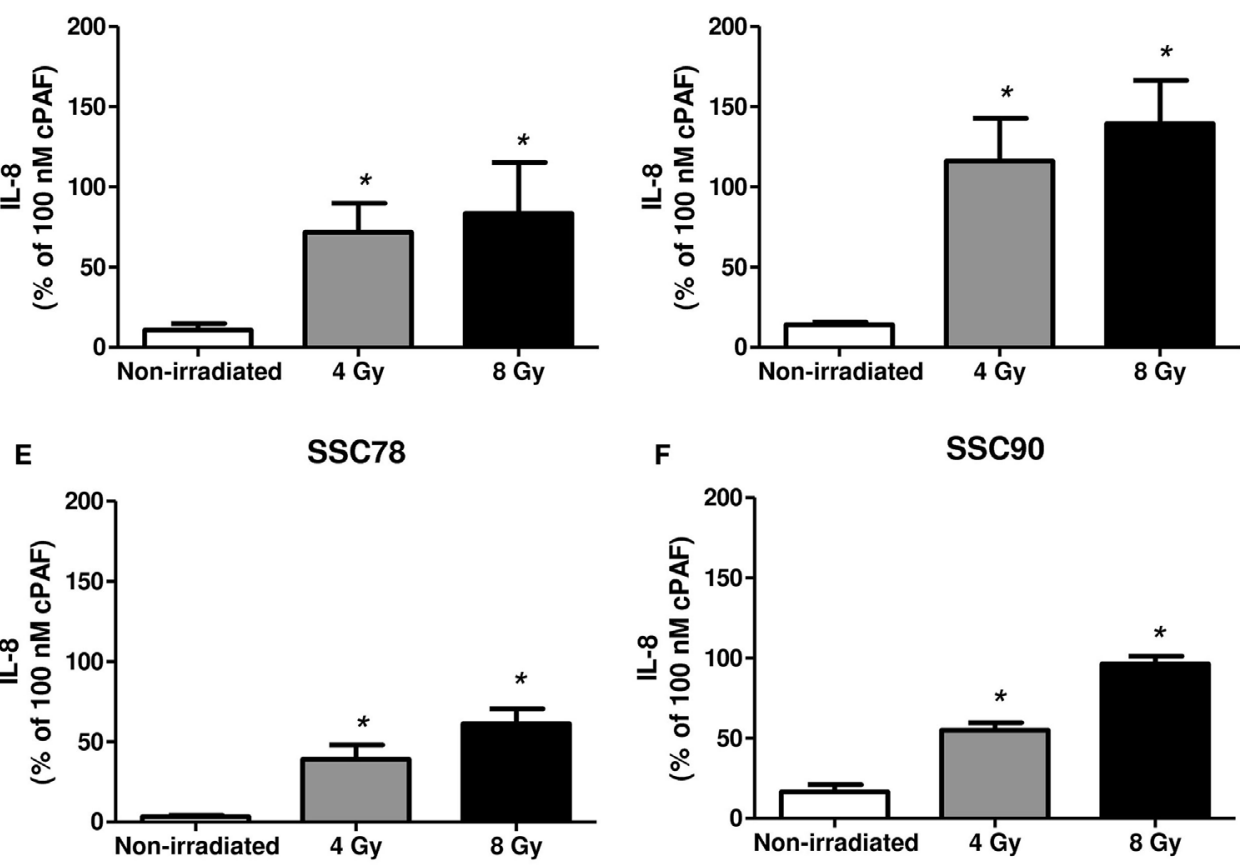

FIGURE 3 | Irradiation of tumor cells induces platelet-activating factor receptor (PAFR) ligands production. Immortalized keratinocytes HaCaT (A), human cervical carcinoma cell lines C33 (B), SiHa (C), and HeLa (D) and head and neck squamous cell carcinoma lineage SCC78 (E) and SCC90 (F) were cultured in RPMI 2\% fetal bovine serum at $37^{\circ} \mathrm{C}$, and $5 \% \mathrm{CO}_{2}$ was irradiated with 4 or $8 \mathrm{~Gy}$. Lipid extracts were obtained after $1 \mathrm{~h}$ following treatment and then added to $\mathrm{KBP}$ cells. After $6 \mathrm{~h}$, interleukin-8 (IL-8) was quantified as a measure of PAFR agonistic activity. As control, PAF (100 nM) was added to KBP cells. Results are expressed as the percentage of IL-8 relative to amounts induced by CPAF. Mean \pm SD of six experiments made in duplicate. ${ }^{*} P<0.05$, comparing irradiated with non-irradiated control. 
higher amounts of mRNA for PAFR than the control HaCaT cell line (Figure 1C). We also evaluated membrane PAFR expression by flow cytometry and observed that $\mathrm{C} 33$, $\mathrm{SiHa}, \mathrm{HeLa}$, and SCC78 cell lines express higher amounts of the receptor in relation to HaCaT cells (Figure 1D).

Next, we assessed whether irradiation would affect PAFR expression in these cell lines. As shown in Figure 2, irradiation of all cell lines in vitro ( 4 or $8 \mathrm{~Gy}$ ) increased PAFR mRNA levels. The lipid extracts from the irradiated cultures obtained as described in Section "Materials and Methods" were then assayed for their capacity to activate PAFR. For this purpose, we developed an assay with carcinoma cells transfected with PAFR (KBP) which secrete (IL-8) in response to receptor activation $(33,34)$. A concentration response curve to the PAFR agonist methylcarbamyl PAF was performed and used to calculate the concentration of PAFR-like lipids present in the supernatants of irradiated cells. This is a very useful assay as it allows the detection of the collection of PAFR ligands generated by irradiation. Figure 3 shows that irradiation induced the secretion of PAFR ligands by all carcinoma cells investigated. These results indicate that PAF-like molecules are produced by radiation and enhance PAFR expression in tumor cells.

Supernatants of the carcinoma cells collected $6 \mathrm{~h}$ after irradiation were measured for PGE2 levels. Figure 4 shows the irradiation-induced dose-dependent generation of PGE2 by all

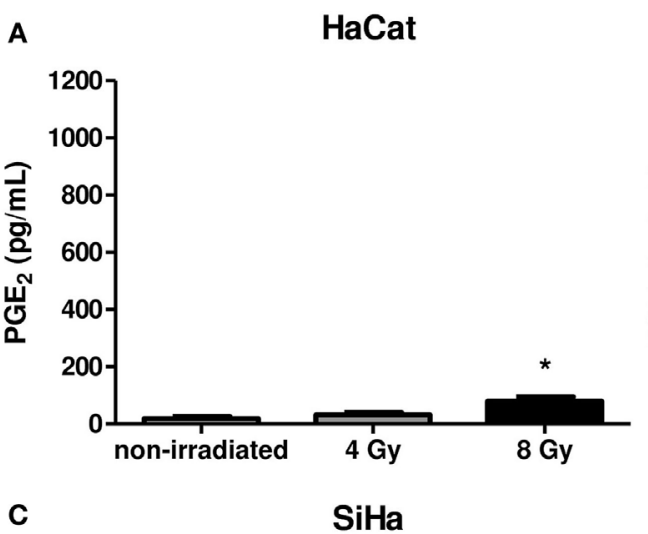

B
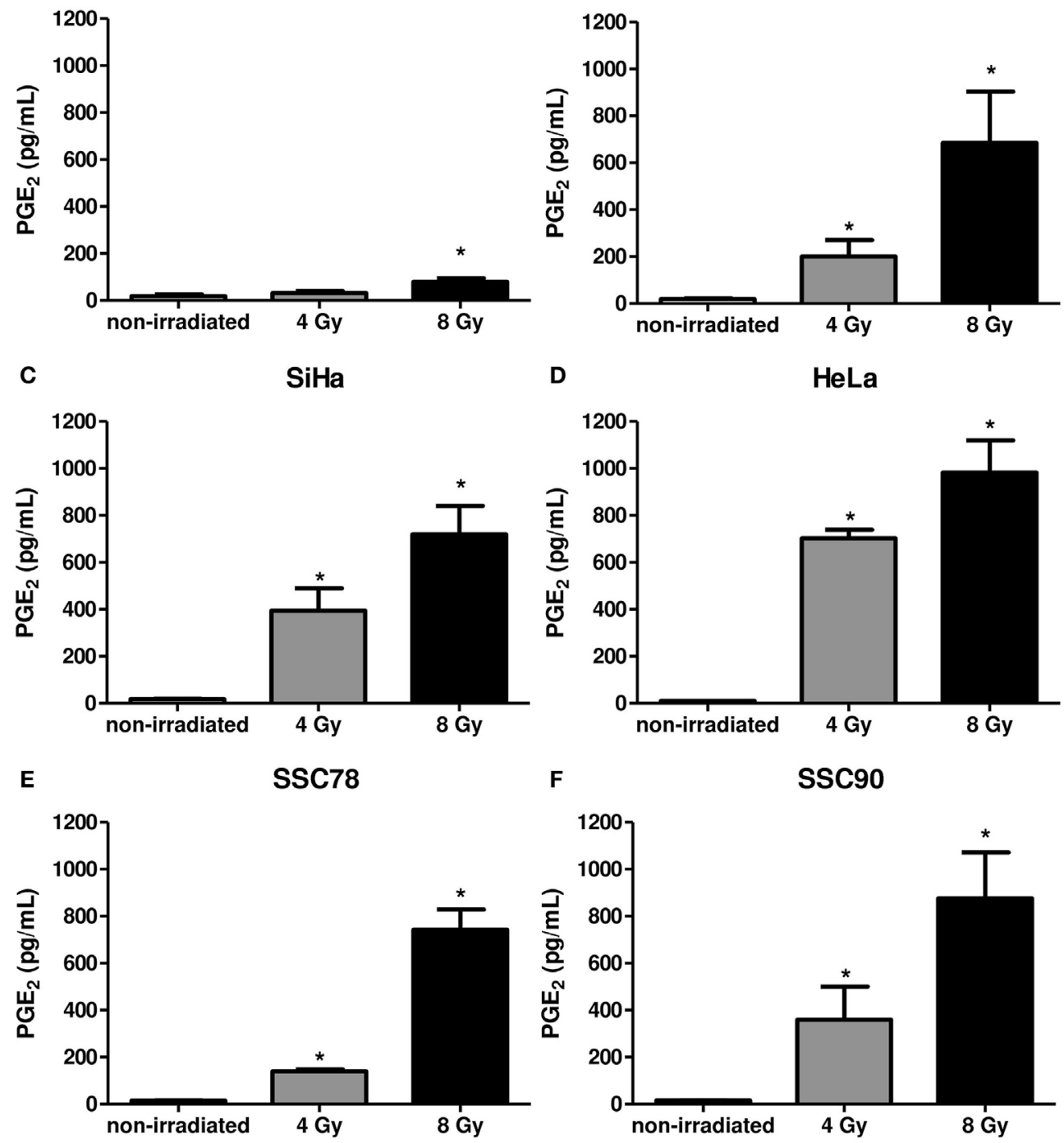

D

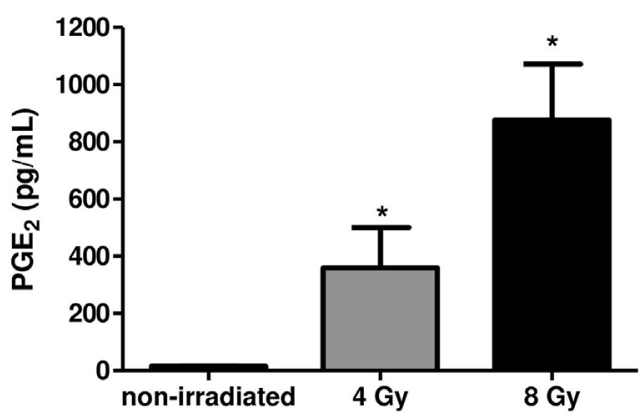

FIGURE 4 | Irradiation of tumor cells induces prostaglandin E2 (PGE2) production. Immortalized keratinocytes HaCaT (A), human cervical carcinoma cell lines C33 (B), SiHa (C), and HeLa (D) and head and neck squamous cell carcinoma lineage SCC78 (E) and SCC90 (F) were cultured in RPMl $2 \%$ fetal bovine serum at $37^{\circ} \mathrm{C}$, and $5 \% \mathrm{CO}_{2}$ was irradiated with 4 or 8 Gy. After 6 hs, the PGE2 production was evaluated in the supernatants. Data are presented as mean \pm SE (standard error) of three independent experiments. ${ }^{*} P<0.05$, comparing irradiated with non-irradiated control. 
tumor cells. Taken together, these results show that in the carcinoma cell lines screened, Gy increased PAFR expression and induced PAF-like molecules and PGE2 generation.

\section{PAFR Activation in Tumor Cells Protects Them from Radiation-Induced Death}

To investigate if PAFR-mediated mechanisms are involved in tumor resistance to radiation, we pretreated the $\mathrm{C} 33, \mathrm{SiHa}$, and HeLa tumor cells with the PAFR antagonist CV3938 before irradiation ( 4 or $8 \mathrm{~Gy}$ ) of the cells and assessed cell death after 3 days. Death was assessed by labeling the tumor cells treated with annexin V and PI and analyzing by flow cytometry. Gy-induced tumor cell death and blockade of PAFR with CV3938 further increased cell death (Figure 5).

In another experimental approach, the human carcinoma cell line (KBM) that does not express PAFR and the same cells transfected with the PAFR (KBP) were irradiated, and the cytotoxic effect of radiation was measured. After $72 \mathrm{~h}$ of exposure to 4 or $8 \mathrm{~Gy}$, the $\mathrm{PAFR}^{+}$cells survived more than the $\mathrm{PAFR}^{-}$cells (Figure 6A), confirming the protective effect of PAF. Furthermore, the KBP cells were treated with a PAFR antagonist or a prostaglandin synthesis inhibitor (indomethacin) before irradiation. Figure 6B shows that the treatment of KBP cells with CV3988 significantly increased radiation-induced cell death, whereas indomethacin did not affect cell survival (Figure 6B). At the dose of indomethacin used, it abolished the PGE2 in the supernatants of irradiated KBP cells (data not shown). In $\mathrm{PAFR}^{-}$cells (Figure 6C), radiation increased cell death, and this was not affected by the treatments. In Figure 7A, we can see that KBP cells irradiated with 8 Gy produced an amount of PAFR ligands equivalent to $92 \%$ of $100 \mathrm{nM}$ of cPAF. KBM did not respond to PAF or to irradiation, although they did respond to phorbol 12-myristate 13-acetate stimulation. Irradiated KBP cells produced PGE2, and this was almost abolished by CV3988 (Figure 7B). These results suggest that PAFR ligands produced during irradiation are more relevant for the radio resistance of tumor cells than prostaglandins.

\section{DISCUSSION}

Previous studies have shown that PAFR activation results in accelerated proliferation, angiogenesis, and metastasis in different models of melanoma, breast, ovarian, and prostate tumors $(9,35,36)$. The association of PAFR antagonists with chemotherapy agents leads to increased tumor cell death and improved treatment effectiveness (14,37-39). We have recently found similar effects with the association of PAFR antagonists and RT $(7,13,40)$. The present study provides additional support for the functional significance of the PAF/PAFR system in tumor RT. Our results show that PTAFR expression was upregulated in cervical cancer clinical samples when compared to normal cervical tissue. Also, PTAFR mRNA level was increased in cervical tumors after RT treatment. In the carcinoma cell lines screened, Gy increased PTARF expression and induced PGE2- and PAF-like lipids. The activation of PAFR by these lipids protects tumor cells from radiation-induced cell death.

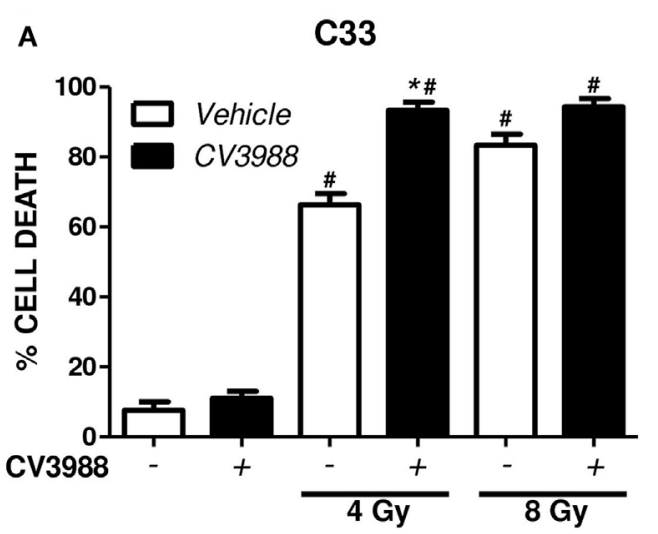

B $\quad \mathrm{SiHa}$
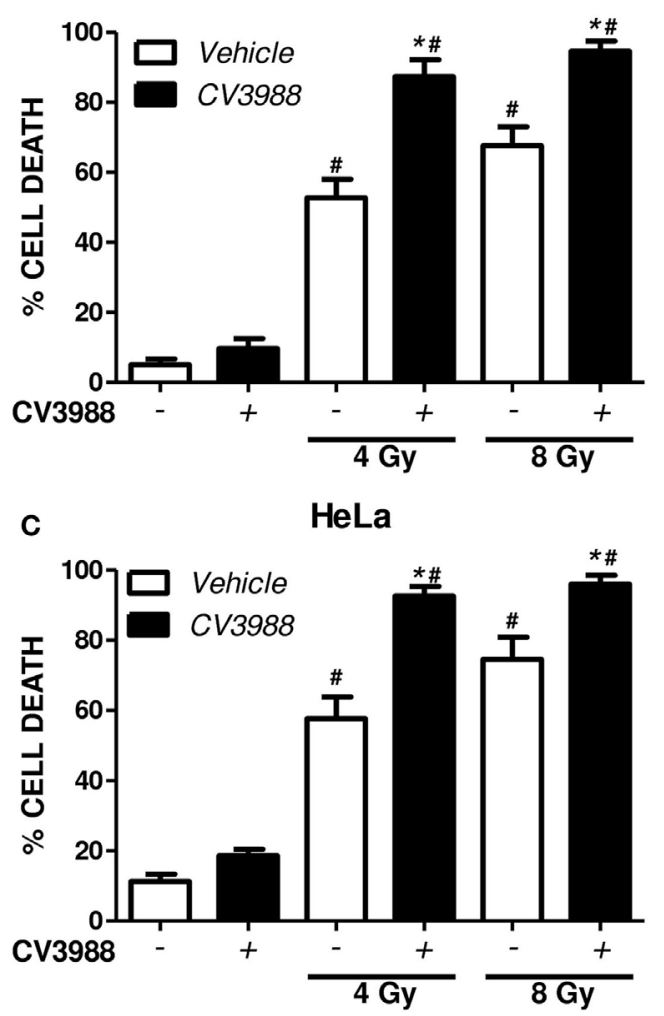

FIGURE 5 | Platelet-activating factor receptor (PAFR) antagonist enhances cell death induced by radiotherapy. C33 (A), SiHa (B), and HeLa (C) cervical carcinoma cell lines were treated (black bars) or not (white bars) with PAFR antagonist (10 $\mu \mathrm{M}$ CV3938) 30 min before irradiation with 4 or 8 Gy. After 3 days, the cultures were trypsinized and stained with annexin V FITC and propidium iodide $(\mathrm{PI})$. Data are shown as the mean $\pm \mathrm{SE}$ (standard error) of the percentage of cells positive for PI and annexin $\mathrm{V}$. ${ }^{\#} P<0.05$ irradiated vs. non-irradiated and ${ }^{*} P<0.05$ treated vs. not treated with PAFR antagonist CV3938. $n=3$ independent experiments performed in duplicate.

Moreover, it seems that the PAFR ligands are more relevant for tumor cell's radio resistance than prostaglandins.

The expression of PAFR is elevated in different types of cancer, such as human hepatocellular carcinoma (41), gastric adenocarcinoma (42), and by several human tumor lineages [e.g., Kaposi's sarcoma cells (43), endometrial cancer cell line HEC-1A (44), 

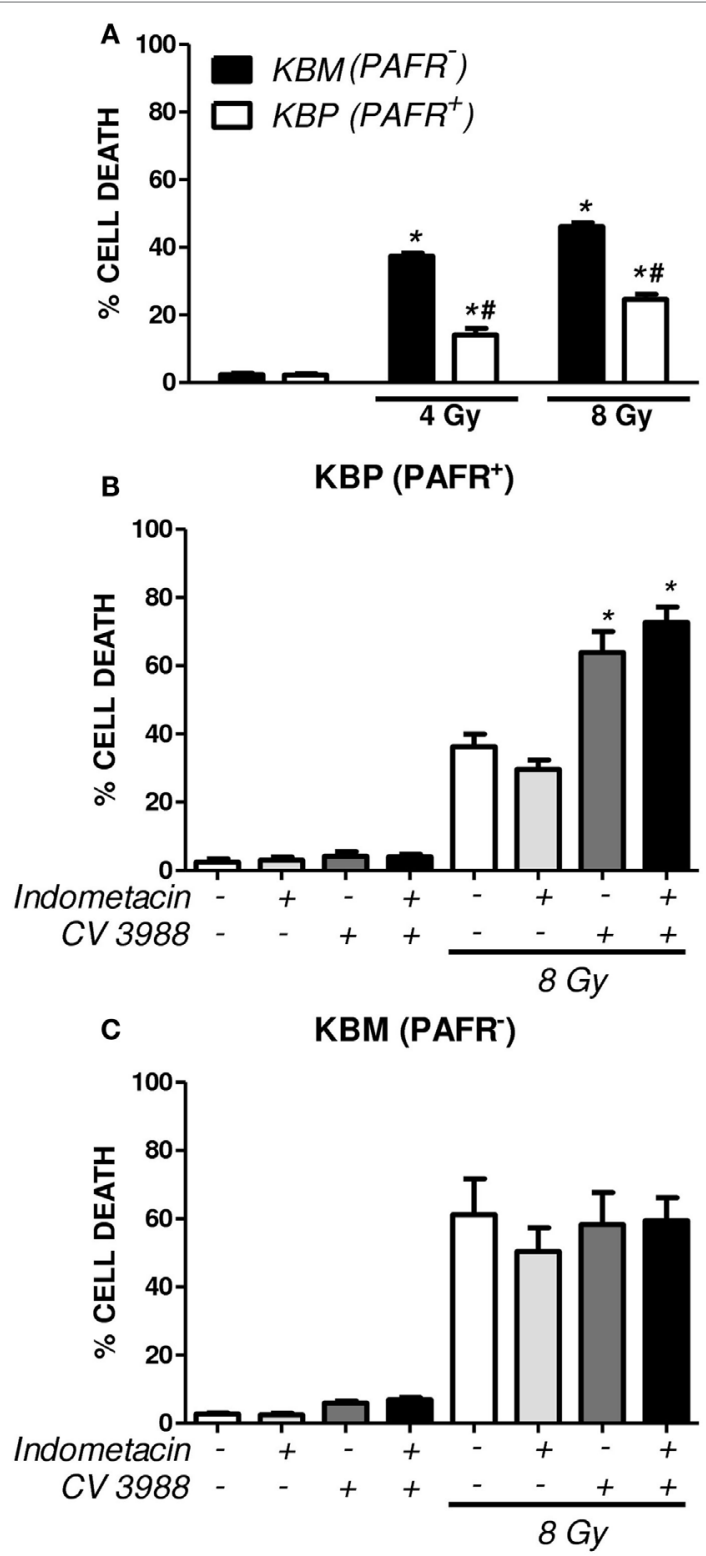

FIGURE 6 | Platelet-activating factor receptor (PAFR) expression protects carcinoma cells from radiation-induced cell death. Human carcinoma cells transfected with PAFR (KBP) and negative for PAFR (KBM) were irradiated with 4 or 8 Gy and incubated for 3 days. (A) Cells were stained with annexin V FITC and propidium iodide (PI), and the percentage of death of cells (annexin/PI-positive cells) was determined $\left({ }^{*} P<0.05 \mathrm{KBM}\right.$ vs. KBP cells; ${ }^{\#} P<0.05$ irradiated vs. non-irradiated). A similar protocol was applied in (B) KBP and (C) KBM cells treated or not with the COX-inhibitor indomethacin $(15 \mu \mathrm{M})$ or PAFR antagonist $(10 \mu \mathrm{M}$ CV3938) 30 min before irradiation. Results are shown as percentage of apoptotic cells ( $\left.{ }^{*} P<0.05\right)$.

epidermoid carcinoma (A431 cells) (45), stomach cancer cell line JR-St (46), and N1E-115 neuroblastoma cells (47)]. Our data show that PAFR is also overexpressed in cervical and head and neck squamous cell carcinoma lineages, which suggest that it may have a role in the pathogenesis and progression of these types of tumors.


FIGURE 7 | Irradiation of tumor cells transfected with PAFR: the production of PAFR agonists and PGE2. Human carcinoma cells transfected with PAFR (KBP) and negative for PAFR (KBM) were cultured in high density $\left(10^{6}\right.$ cells/ $\mathrm{mL}$ ) and were treated or not with gamma irradiation (8 Gy). (A) Interleukin-8 (IL-8) concentration in cell supernatants $6 \mathrm{~h}$ after irradiation was quantified by ELISA as a measure of molecules with agonist activity on the PAF receptor. As control, cPAF (100 nM) or phorbol 12-myristate 13-acetate (PMA) $(1,000 \mathrm{nM})$ was added to cells. (B) PGE2 concentration in cell supernatants $1 \mathrm{~h}$ after irradiation. Results are expressed as the median $\pm \mathrm{SE}$ (standard error) of three experiments made in duplicate. $P<0.05 \mathrm{KBM}$ vs. KBP cells; ${ }^{\#} P<0.05$ treated vs. not treated with PAFR antagonist CV3938.

Previous studies from our laboratory showed that the stimulation of a cell line positive for PAFR (KBP) with cPAF increased cell proliferation; however, this did not occur in PAFR- (KBM) control cells (7). Also, the activation of PAFR induces the phosphorylation of ERK and p38 MAP kinase in KBP cells, which stimulates cell proliferation (48). PAF seems to have a role in tumor growth in normal conditions, since transgenic mice overexpressing PAFR exhibited increased local cell growth in the skin, characterized by dermal and epidermal hyperthickening with dermal melanosis, and in some aged mice, spontaneous development of melanocytic tumors (48) occurred.

Some previous studies have also linked the PAF/PAFR axis with cellular responses to stress and cellular damage. Different stimuli including cytokines (49), cigarette smoke (27), ultraviolet B (28), and gamma irradiation (13) resulted in significant levels of PAF synthesis by tumors cells. The approach used in this study was to induce irradiation stress in tumors cells after the inhibition of PAFR to enhance the sensitivity of cancer cells toward radiation. The present study was performed with a gamma irradiator 
at various radiation doses ( 4 and $8 \mathrm{~Gy}$ ). It is well established that radiation sensitivity mechanisms in human cancers are determined by intracellular factors (18). Conversely, in this study, we demonstrate that upon different doses of radiation, cervical tumor cells and head and neck carcinoma cells respond by increasing PAFR expression and producing a great deal of PAFR ligands that could affect cell survival. Previous work from Seo et al. (16) showed that PAFR activation induces the upregulation of antiapoptotic gene products, such as Bcl-2, thus attenuating the cytotoxic effect of chemotherapeutic agents. Like this, specific PAFR antagonists may have a potential effect in blocking protective tumor responses and potentiating RT.

In fact, the simultaneous association of PAFR antagonists with low doses of radiation increased cell death induced by cell damage, demonstrating the protective effect of the PAFR on tumor cell lines. In addition, the irradiation-induced PAF ligands signaling cascade alone was sufficient to induce PGE production, which in turn is highly associated with the activation of antiapoptotic pathways $(50,51)$ and the phenomenon of tumor repopulation induced by RT $(8,52,53)$.

To support our hypothesis that PAFR can protect cells from irradiation-induced apoptosis via PGE production, we demonstrate that irradiated $\mathrm{PAFR}^{+}$tumor cells show greater resistance to radiation-induced cell death than PAFR tumor cells. This resistance was suppressed by treatment with the CV3988 antagonist. An additional effect on the loss of radio resistance to cell death was observed by treatment with the prostaglandin inhibitor indomethacin. This evidence supports our conclusion that PAFR expression is positively correlated with cell survival.

\section{REFERENCES}

1. Small W, Bacon MA, Bajaj A, Chuang LT, Fisher BJ, Harkenrider MM, et al. Cervical cancer: a global health crisis. Cancer (2017) 123(13):2404-12. doi:10.1002/cncr.30667

2. Mohanti BK, Thakar A, Kaur J, Bahadur S, Malik M, Gandhi AK, et al. Postoperative radiotherapy dose requirement in standard combined-modality practice for head and neck squamous cell carcinoma: analysis of salient surgical and radiotherapy parameters in 2 cohorts. Head Neck (2017) 39(9):1788-96. doi:10.1002/hed.24836

3. Jäger R, Fearnhead HO. Dead cells talking: the silent form of cell death is not so quiet. Biochem Res Int (2012) 2012:8. doi:10.1155/2012/453838

4. Ichim G, Tait SWG. A fate worse than death: apoptosis as an oncogenic process. Nat Rev Cancer (2016) 16(8):539-48. doi:10.1038/nrc.2016.58

5. Correa M, Machado J, Carneiro CRW, Pesquero JB, Bader M, Travassos LR, et al. Transient inflammatory response induced by apoptotic cells is an important mediator of melanoma cell engraftment and growth. Int J Cancer (2005) 114(3):356-63. doi:10.1002/ijc.20673

6. Bachi ALL, Dos Santos LC, Nonogaki S, Jancar S, Jasiulionis MG. Apoptotic cells contribute to melanoma progression and this effect is partially mediated by the platelet-activating factor receptor. Mediators Inflamm (2012) 2012:610371. doi:10.1155/2012/610371

7. da Silva-Jr IA, Chammas R, Lepique AP, Jancar S. Platelet-activating factor (PAF) receptor as a promising target for cancer cell repopulation after radiotherapy. Oncogenesis (2017) 6(1):e296. doi:10.1038/oncsis.2016.90

8. Huang Q, Li F, Liu X, Li W, Shi W, Liu F-F, et al. Caspase 3-mediated stimulation of tumor cell repopulation during cancer radiotherapy. Nat Med (2011) 17(7):860-6. doi:10.1038/nm.2385

9. Jancar S, Chammas R. PAF receptor and tumor growth. Curr Drug Targets (2014) 15(10):982-7. doi:10.2174/1389450115666140903111812

\section{CONCLUSION}

Together, our data suggest that (1) radiation induces PAFR expression and the corresponding ligands (PAF-like molecules) and (2) the inhibition of PAFR selectively enhances the sensitivity of cervical carcinoma and squamous carcinoma cells to radiation treatment. These results are of potential interest as they widen the field of investigation into the roles of PAFR and support the concept that PAFR antagonists may be useful for adjuvant therapy, improving the efficacy of RT.

\section{AUTHOR CONTRIBUTIONS}

IA and SJ participated in the conception and design of the study; IA, BD, and SH performed acquisition of data, analysis, and interpretation of data; and IA, SJ, and AL wrote the manuscript.

\section{ACKNOWLEDGMENTS}

We would like to sincerely thank Marlise B. A. Montes and Sandra Alexandra da Silva for the expert technical support.

\section{FUNDING}

This work was supported by Fundação de Amparo à Pesquisa do Estado de São Paulo (FAPESP Grant number 2013/15-719-0 and 2017/08904-7) and Conselho Nacional de Desenvolvimento Científico e Tecnológico (CNPq Grant number 302903/2016-0).

10. Prescott SM, Zimmerman GA, Stafforini DM, McIntyre TM. Plateletactivating factor and related lipid mediators. Annu Rev Biochem (2000) 69:419-45. doi:10.1146/annurev.biochem.69.1.419

11. McIntyre TM. Bioactive oxidatively truncated phospholipids in inflammation and apoptosis: formation, targets, and inactivation. Biochim Biophys Acta (2012) 1818:2456-64. doi:10.1016/j.bbamem.2012.03.004

12. Yamamori T, Yasui H, Yamazumi M, Wada Y, Nakamura Y, Nakamura H, et al. Ionizing radiation induces mitochondrial reactive oxygen species production accompanied by upregulation of mitochondrial electron transport chain function and mitochondrial content under control of the cell cycle checkpoint. Free Radic Biol Med (2012) 53(2):260-70. doi:10.1016/j.freeradbiomed.2012.04.033

13. Sahu RP, Harrison KA, Weyerbacher J, Murphy RC, Konger RL, Garrett JE, et al. Radiation therapy generates platelet-activating factor agonists. Oncotarget (2016) 7(15):20788-800. doi:10.18632/oncotarget.7878

14. Onuchic AC, MacHado CML, Saito RF, Rios FJ, Jancar S, Chammas R. Expression of PAFR as part of a prosurvival response to chemotherapy: a novel target for combination therapy in melanoma. Mediators Inflamm (2012) 2012:10-5. doi:10.1155/2012/175408

15. Bussolati B, Biancone L, Cassoni P, Russo S, Rola-Pleszczynski M, Montrucchio $\mathrm{G}$, et al. PAF produced by human breast cancer cells promotes migration and proliferation of tumor cells and neo-angiogenesis. Am J Pathol (2000) 157(5):1713-25. doi:10.1016/S0002-9440(10)64808-0

16. Heon Seo K, Ko H-M, Kim H-A, Choi J-H, Jun Park S, Kim K-J, et al. Platelet-activating factor induces up-regulation of antiapoptotic factors in a melanoma cell line through nuclear factor-kappaB activation. Cancer Res (2006) 66(9):4681-6. doi:10.1158/0008-5472.CAN-05-3186

17. Eberhart CE, Coffey RJ, Radhika A, Giardiello FM, Ferrenbach S, DuBois RN. Up-regulation of cyclooxygenase 2 gene expression in human colorectal adenomas and adenocarcinomas. Gastroenterology (1994) 107(4):1183-8. doi:10.1016/0016-5085(94)90246-1 
18. Koga H, Sakisaka S, Ohishi M, Kawaguchi T, Taniguchi E, Sasatomi K, et al. Expression of cyclooxygenase-2 in human hepatocellular carcinoma: relevance to tumor dedifferentiation. Hepatology (1999) 29(3):688-96. doi:10.1002/hep.510290355

19. Cheng JC, Bai A, Beckham TH, Tucker Marrison S, Yount CL, Young K, et al. Radiation-induced acid ceramidase confers prostate cancer resistance and tumor relapse. J Clin Invest (2013) 123(10):4344-58. doi:10.1172/JCI64791

20. Liu B, Qu L, Yan S. Cyclooxygenase-2 promotes tumor growth and suppresses tumor immunity. Cancer Cell Int (2015) 15:106. doi:10.1186/s12935015-0260-7

21. Hida T, Yatabe Y, Achiwa H, Muramatsu H, Kozaki K, Nakamura S, et al. Increased expression of cyclooxygenase 2 occurs frequently in human lung cancers, specifically in adenocarcinomas. Cancer Res (1998) 58(17):3761-4.

22. DeNardo DG, Andreu P, Coussens LM. Interactions between lymphocytes and myeloid cells regulate pro- versus anti-tumor immunity. Cancer Metastasis Rev (2010) 29(2):309-16. doi:10.1007/s10555-010-9223-6

23. Mantovani A, Allavena P, Sica A, Balkwill F. Cancer-related inflammation. Nature (2008) 454(7203):436-44. doi:10.1038/nature07205

24. Pang LY, Hurst EA, Argyle DJ. Cyclooxygenase-2: a role in cancer stem cell survival and repopulation of cancer cells during therapy. Stem Cells Int (2016) 2016:1-11. doi:10.1155/2016/2048731

25. Fang HY, Lin T-S, Lin J-P, Wu YC, Chow K-C, Wang L-S. Cyclooxygenase-2 in human non-small cell lung cancer. Eur J Surg Oncol (2003) 29(2):171-7. doi:10.1053/ejso.2002.1316

26. Yao Y, Wolverton JE, Zhang Q, Marathe GK, Al-Hassani M, Konger RL, et al. Ultraviolet B radiation generated platelet-activating factor receptor agonist formation involves EGF-R-mediated reactive oxygen species. J Immunol (2009) 182(5):2842-8. doi:10.4049/jimmunol.0802689

27. Sahu RP, Petrache I, Van Demark MJ, Rashid BM, Ocana JA, Tang Y, et al. Cigarette smoke exposure inhibits contact hypersensitivity via the generation of platelet-activating factor agonists. J Immunol (2013) 190(5):2447-54. doi:10.4049/jimmunol.1202699

28. Marathe GK, Johnson C, Billings SD, Southall MD, Pei Y, Spandau D, et al. Ultraviolet B radiation generates platelet-activating factor-like phospholipids underlying cutaneous damage. J Biol Chem (2005) 280(42):35448-57. doi:10.1074/jbc.M503811200

29. Ferracini M, Sahu RP, Harrison KA, Waeiss RA, Murphy RC, Jancar S, et al. Topical photodynamic therapy induces systemic immunosuppression via generation of platelet-activating factor receptor ligands. J Invest Dermatol (2015) 135(1):321-3. doi:10.1038/jid.2014.313

30. Livak KJ, Schmittgen TD. Analysis of relative gene expression data using realtime quantitative PCR and the 2(-Delta Delta C(T)) method. Methods (2001) 25(4):402-8. doi:10.1006/meth.2001.1262

31. Scotto L, Narayan G, Nandula SV, Arias-Pulido H, Subramaniyam S, Schneider A, et al. Identification of copy number gain and overexpressed genes on chromosome arm $20 \mathrm{q}$ by an integrative genomic approach in cervical cancer: potential role in progression. Genes Chromosomes Cancer (2008) 47(9):755-65. doi:10.1002/gcc.20577

32. Iwakawa $M$, Ohno $T$, Imadome $K$, Nakawatari $M$, Ishikawa $K$, Sakai $M$, et al. The radiation-induced cell-death signaling pathway is activated by concurrent use of cisplatin in sequential biopsy specimens from patients with cervical cancer. Cancer Biol Ther (2007) 6(6):905-11. doi:10.4161/ cbt.6.6.4098

33. Travers JB, Huff JC, Rola-Pleszczynski M, Gelfand EW, Morelli JG, Murphy RC. Identification of functional platelet-activating factor receptors on human keratinocytes. J Invest Dermatol (1995) 105(6):816-23. doi:10.1111/15231747.ep12326581

34. Filgueiras LR, Koga MM, Quaresma PG, Ishizuka EK, Montes MBA, Prada PO, et al. PAFR in adipose tissue macrophages is associated with anti-inflammatory phenotype and metabolic homoeostasis. Clin Sci (2016) 130(8):601-12. doi:10.1042/CS20150538

35. Kume K, Shimizu T. Platelet-activating factor (PAF) induces growth stimulation, inhibition, and suppression of oncogenic transformation in NRK cells overexpressing the PAF receptor. J Biol Chem (1997) 272(36):22898-904. doi:10.1074/jbc.272.36.22898

36. de Oliveira SI, Fernandes PD, Amarante Mendes JGP, Jancar S. Phagocytosis of apoptotic and necrotic thymocytes is inhibited by PAF-receptor antagonists and affects LPS-induced COX-2 expression in murine macrophages. Prostaglandins Other Lipid Mediat (2006) 80(1-2):62-73. doi:10.1016/j. prostaglandins.2006.04.002

37. Sahu RP, Ocana JA, Harrison KA, Ferracini M, Touloukian CE, Al-Hassani M, et al. Chemotherapeutic agents subvert tumor immunity by generating agonists of platelet-activating factor. Cancer Res (2014) 74(23):7069-78. doi:10.1158/0008-5472.CAN-14-2043

38. Yu Y, Zhang M, Zhang X, Cai Q, Hong S, Jiang W, et al. Synergistic effects of combined platelet-activating factor receptor and epidermal growth factor receptor targeting in ovarian cancer cells. J Hematol Oncol (2014) 7(1):39. doi:10.1186/1756-8722-7-39

39. Sahu RP, Ferracini M, Travers JB. Systemic chemotherapy is modulated by platelet-activating factor-receptor agonists. Mediators Inflamm (2015) 2015:820543. doi:10.1155/2015/820543

40. Yao B, Liu B, Shi L, Li X, Ren C, Cai M, et al. PAFR selectively mediates radioresistance and irradiation-induced autophagy suppression in prostate cancer cells. Oncotarget (2017) 8(8):13846-54. doi:10.18632/oncotarget. 14647

41. Kitagawa D, Taketomi A, Kayashima H, Kuroda Y, Itoh S, Yamashita Y-I, et al. Expression of platelet-activating factor receptor: a novel prognosticator in patients with hepatocellular carcinoma following hepatectomy. Oncology (2007) 72(5-6):381-7. doi:10.1159/000113149

42. Giaginis C, Kourou E, Giagini A, Goutas N, Patsouris E, Kouraklis G, et al. Platelet-activating factor (PAF) receptor expression is associated with histopathological stage and grade and patients' survival in gastric adenocarcinoma. Neoplasma (2014) 61(3):309-17. doi:10.4149/neo_ 2014040

43. Bussolino F, Arese M, Montrucchio G, Barra L, Primo L, Benelli R, et al. Platelet activating factor produced in vitro by Kaposi's sarcoma cells induces and sustains in vivo angiogenesis. J Clin Invest (1995) 96(2):940-52. doi:10.1172/JCI118142

44. Maggi M, Bonaccorsi L, Finetti G, Carloni V, Muratori M, Laffi G, et al. Platelet-activating factor mediates an autocrine proliferative loop in the endometrial adenocarcinoma cell line HEC-1A. Cancer Res (1994) 54(17): 4777-84.

45. Tripathi YB, Kandala JC, Guntaka RV, Lim RW, Shukla SD. Platelet activating factor induces expression of early response genes c-fos and TIS-1 in human epidermoid carcinoma A-431 cells. Life Sci (1991) 49(23):1761-7. doi:10.1016/0024-3205(91)90319-7

46. Mutoh H, Ishii S, Izumi T, Kato S, Shimizu T. Platelet-activating factor (PAF) positively auto-regulates the expression of human PAF receptor transcript 1 (leukocyte-type) through NF-kappa B. Biochem Biophys Res Commun (1994) 205(2):1137-42. doi:10.1006/bbrc.1994.2784

47. Lalouette F, Diserbo M, Martin C, Verdetti J, Fatome M. Presence of specific platelet-activating factor binding-sites in neuroblastoma N1E-115 cells. Neurosci Lett (1995) 186(2-3):173-6. doi:10.1016/0304-3940(95) 11319-R

48. Sato S, Kume K, Ito C, Ishii S, Shimizu T. Accelerated proliferation of epidermal keratinocytes by the transgenic expression of the platelet-activating factor receptor. Arch Dermatol Res (1999) 291(11):614-21. doi:10.1007/ s004030050463

49. Yu Y, Zhang X, Hong S, Zhang M, Cai Q, Jiang W, et al. Epidermal growth factor induces platelet-activating factor production through receptors transactivation and cytosolic phospholipase A2 in ovarian cancer cells. J Ovarian Res (2014) 7:39. doi:10.1186/1757-2215-7-39

50. Leone V, di Palma A, Ricchi P, Acquaviva F, Giannouli M, Di Prisco AM, et al. PGE2 inhibits apoptosis in human adenocarcinoma Caco-2 cell line through Ras-PI3K association and cAMP-dependent kinase A activation. Am J Physiol Gastrointest Liver Physiol (2007) 293(4):G673-81. doi:10.1152/ ajpgi.00584.2006

51. Liou J-Y, Ellent DP, Lee S, Goldsby J, Ko B-S, Matijevic N, et al. Cyclooxygenase-2-derived prostaglandin e2 protects mouse embryonic stem cells from apoptosis. Stem Cells (2007) 25(5):1096-103. doi:10.1634/ stemcells.2006-0505

52. Cheng J, Tian L, Ma J, Gong Y, Zhang Z, Chen Z, et al. Dying tumor cells stimulate proliferation of living tumor cells via caspase-dependent protein kinase C $\delta$ activation in pancreatic ductal adenocarcinoma. Mol Oncol (2015) 9(1):105-14. doi:10.1016/j.molonc.2014.07.024 
53. Donato AL, Huang Q, Liu X, Li F, Zimmerman MA, Li C-Y. Caspase 3 promotes surviving melanoma tumor cell growth after cytotoxic therapy. J Invest Dermatol (2014) 134(6):1686-92. doi:10.1038/jid.2014.18

Conflict of Interest Statement: The authors declare that the research was conducted in the absence of any commercial or financial relationships that could be construed as a potential conflict of interest.
Copyright (ङ) 2018 da Silva-Junior, Dalmaso, Herbster, Lepique and Jancar. This is an open-access article distributed under the terms of the Creative Commons Attribution License (CC BY). The use, distribution or reproduction in other forums is permitted, provided the original author(s) and the copyright owner are credited and that the original publication in this journal is cited, in accordance with accepted academic practice. No use, distribution or reproduction is permitted which does not comply with these terms. 